\begin{abstract}
UNIVERSIDADE DE BRASÍLIA
Faculdade de Educação - UAB/UnB/MEC/SECAD

Curso de Especialização em Educação na Diversidade e

Cidadania, com ênfase em EJA
\end{abstract}

\author{
AMÁLIA BALIZA RODRIGUES \\ CLEIDE CORDEIRO DOS SANTOS \\ ELAINE MARIA MACHADO BARBOSA \\ RENATA CÂNDIDO DA SILVA
}

\title{
A IMPORTÂNCIA DE VALORIZAR A AUTO-ESTIMA NA EDUCAÇÃO DE JOVENS E ADULTOS
}

ANÁPOLIS, GO

Junho/2010 


\author{
UNIVERSIDADE DE BRASÍLIA \\ Faculdade de Educação - UAB/UnB/MEC/SECAD \\ Curso de Especialização em Educação na Diversidade e \\ Cidadania, com ênfase em EJA
}

\title{
A IMPORTÂNCIA DE VALORIZAR A AUTO-ESTIMA NA EDUCAÇÃO DE JOVENS E ADULTOS
}

\author{
AMÁLIA BALIZA RODRIGUES \\ CLEIDE CORDEIRO DOS SANTOS \\ ELAINE MARIA MACHADO BARBOSA \\ RENATA CÂNDIDO DA SILVA
}

\begin{abstract}
Prof ${ }^{a}$. Doutora Maria Margarida Machado
(Professora Orientadora)

Prof ${ }^{-}$. Ms. Juliana Alves de Araujo Bottechia

(Tutora Orientadora)
\end{abstract}

Projeto de Intervenção Local (PIL) - TURMA “J” 


\author{
ANÁPOLIS, GO - Junho/2010 \\ UNIVERSIDADE DE BRASÍLIA \\ Faculdade de Educação - UAB/UnB/MEC/SECAD \\ Curso de Especialização em Educação na Diversidade e \\ Cidadania, com ênfase em EJA
}

AMÁLIA BALIZA RODRIGUES

CLEIDE CORDEIRO DOS SANTOS

ELAINE MARIA MACHADO BARBOSA

RENATA CÂNDIDO DA SILVA

\title{
A IMPORTÂNCIA DE VALORIZAR A AUTO-ESTIMA NA EDUCAÇÃO DE JOVENS E ADULTOS
}

Trabalho apresentado a Universidade de Brasília como pré requisito parcial para obtenção do Título de Especialista em Educação na Diversidade e Cidadania, com ênfase em EJA.

Prof ${ }^{a}$. Doutora Maria Margarida Machado

(Professora Orientadora)

Prof ${ }^{a}$. Ms. Juliana Alves de Araujo Bottechia

(Tutora Orientadora) 
ANÁPOLIS, GO - Junho/2010

"Ensinar é um exercício de imortalidade. De alguma forma continuamos a viver naqueles, cujos olhos aprenderam a ver 0 mundo pela magia da nossa palavra, o professor assim, não morre jamais". 


\section{Rubem Alves}

\section{RESUMO}

O presente Projeto de Intervenção Local buscou trabalhar a auto-estima dos alunos da Educação de Jovens e Adultos na Escola Municipal Clovis Guerra. Ao estudar o fator descrito, considerando faixa etária, posição social de cada um, gênero, submissão, consumo de drogas, evasão escolar e retorno à escola após longo tempo de desistência, foi o desafio da equipe em realizar este trabalho; Onde causou expectativas e resultados, estresse e alegrias, ensino e aprendizagem dentro do proposto, levando aos alunos algo que eles apreciassem e que fosse possível um bom aproveitamento das atividades. Os alunos assistiram a palestras, fizeram trabalhos diversos, praticaram a leitura e se conscientizaram da importância do estudo para se ingressarem no mercado de trabalho com mais confiança. Os resultados obtidos apresentaram uma melhoria visível nos alunos da EJA, pois foram transmitidos ensinamentos e troca de conhecimento para gerações futuras.

Palavras-Chaves: Ensino, EJA, educação e aprendizado. 


\section{1 - LISTA DE TABELAS}

Tabela 1 - Quais são os maiores problemas de sua vida escolar? / Pag. 20

Tabela 2 - Se você fosse mudar algo em sua vida, o que mudaria? / Pag. 20

Tabela 3 - Quais são os seus sonhos? / Pag. 21 


\section{2 - LISTA DE ILUSTRAÇÕES}

Figura 1 - Foto com o palestrante Sr. Elia, palestra As drogas e suas consequências / Pag. 22 Figura 2 - Foto com o palestrante Sr. Jailton, palestra sobre auto-estima e valorização pessoal / Pag. 23

Figura 3 - Foto com alunos da EJA confeccionando bolas para o trabalho interdisciplinar (EJA Cores e Valores na Copa do Mundo) / Pag. 23

Figura 4 - Foto da apresentação artística dos alunos da EJA (EJA - Cores e Valores na Copa do Mundo) / Pag. 24

Figura 5 - Fotos com os alunos da EJA fazendo atividades no laboratório de informática / Pag. 25

Figura 6 - Fotos do interclasse entre alunos da EJA (noturno) e alunos do Ensino Regular (matutino) / Pag. 26

Figura 7 - Fotos da culminância do projeto entre os alunos da EJA (noturno) e Ensino Regular (matutino) na Festa Junina / Pag. 27 


\section{3 - ATIVIDADES REALIZADAS}

1 - Atividade Realizada - Língua Portuguesa / Pág. 28

2 - Atividade Realizada - Laboratório de Informática / Pág. 29

3 - Atividade Realizada - Matemática / Pág. 29 


\section{SUMÁRIO}

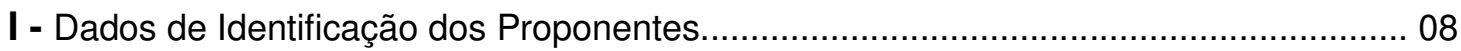

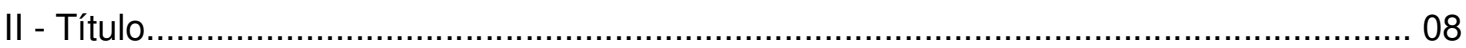

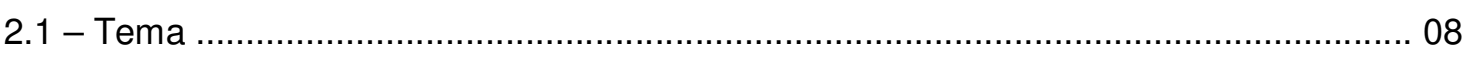

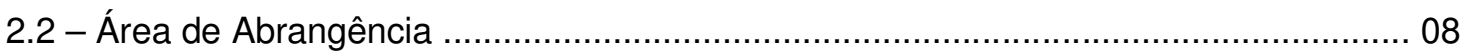

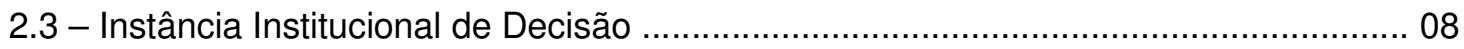

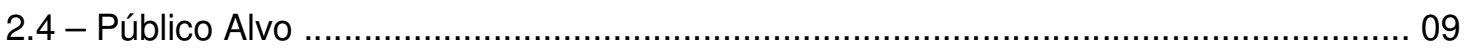

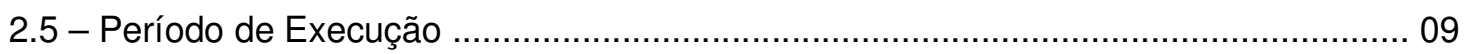

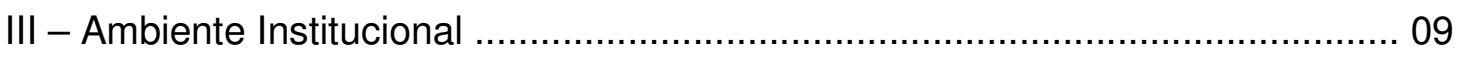

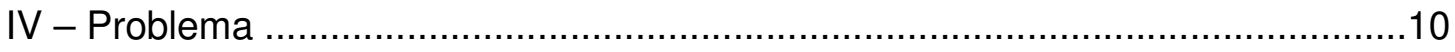

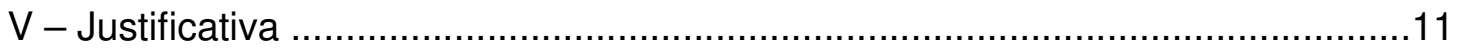

$\mathrm{VI}$ - Objetivo Geral ...........................................................................12

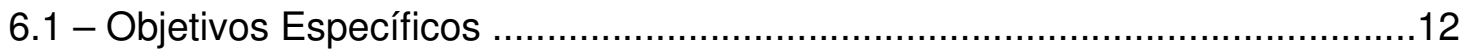

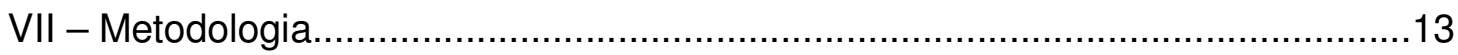

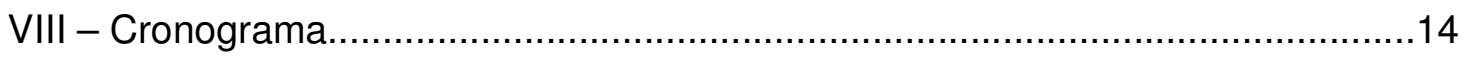

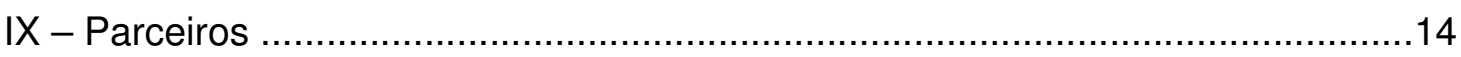

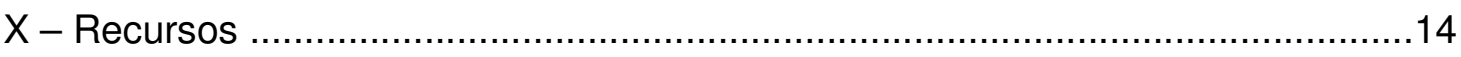

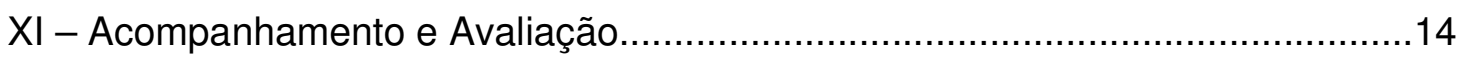

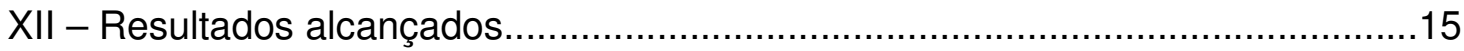

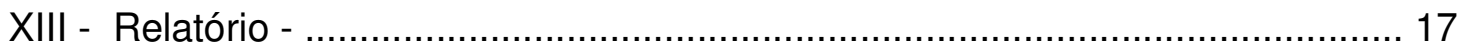

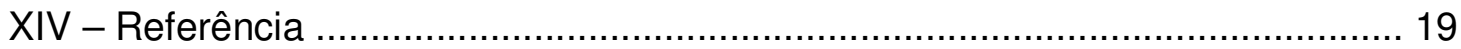

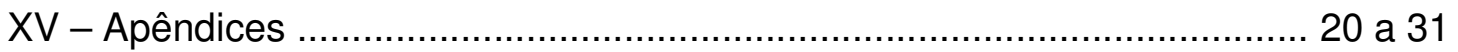

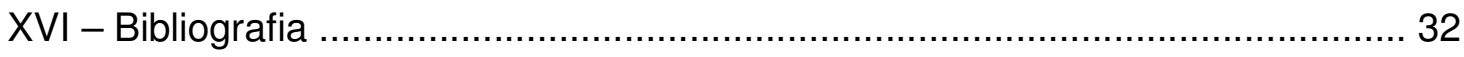




\section{I - DADOS DE IDENTIFICAÇÃO DOS PROPONENTES}

AMÁLIA BALIZA RODRIGUES

Rua Afonso Prado Q. 11 Lt. 06 Apt. 201 Maracanã - Tel. (62)33150821

email: baliza_2004@hotmail.com

CLEIDE CORDEIRO DOS SANTOS

Rua Joaquim Gomes Pereira № 49 Centro - Campo Limpo de Goiás

Tel. (62) 81429732 - email: cleidefisma@hotmail.com

ELAINE MARIA MACHADO BARBOSA

Rua Quintino Bacaiúva, 610 Centro - Tel. (62)84404019

email: prof_elainemachado@yahoo.com.br

RENATA CÂNDIDO DA SILVA

Rua Pernambuco Qd. B Lt. 10 Anexo Itamaraty - Tel. (62)99956153

email: renatabentons@gmail.com

\section{II - TíTULO}

A importância de valorizar a auto-estima na Educação de Jovens e Adultos

\section{1 - TEMA}

Droga, submissão ao marido, violência pelo uso de drogas, desemprego, sentimento de inferioridade e evasão escolar.

\section{2 - ÁREA DE ABRANGÊNCIA}

Escola Municipal Clovis Guerra, Avenida Planalto Qd. 12 Lt. 02 Vila Jaiara CEP 75064 - 720 - Anápolis - Goiás

2.3 - INSTÂNCIA INSTITUCIONAL DE DECISÃO

- Governo Municipal

- Secretaria de Educação - Coordenação da EJA

- Escola Municipal e Conselho Escolar

- Diretora

- Coordenadores

- Professores

- Alunos da EJA

2.4 - PÚBLICO ALVO 
Voltado a compreender a realidade dos alunos da EJA em nossa escola, criamos o PIL para minimizar o problema da auto-estima causada pelo uso de drogas (levando a violência), desemprego, submissão ao marido, chegando à evasão escolar; no projeto estaremos trabalhando dinâmicas voltadas para o valor de cada um, levando o aluno a se sentir um ser humano capaz de atuar em seu meio social, sem complexo de inferioridade.

\section{5 - PERÍODO DE EXECUÇÃO}

Fevereiro de 2010 com término previsto para junho do mesmo ano, porém a perspectiva é de ultrapassar este período (e até sair dos muros da escola), porque visa melhorar a auto-estima com ações propícias para o crescimento individual.

\section{III - AMBIENTE INSTITUCIONAL}

- HISTÓRICO DA ESCOLA

A Escola foi criada a partir da insistência do Padre Tiago, do Planejamento de Jonas Ferreira Duarte diretor executivo, construída pela construtora Agroenge, organizado por Nadir de Souza Andrade e pelo prefeito Jamel Cecílio.

A Escola foi inaugurada no ano de 1978 com o nome de Centro de Ensino de 1․ Grau Lúcia Vânia Abrão Costa, em sua homenagem como Primeira Dama do Estado. Em 1978 publicou-se a Lei 703/78 que denominou Centro de Ensino de 1ํㅡㄴ Grau Clovis Guerra.

No ano de 1986 passou a chamar Escola Municipal Clovis Guerra, denominada pela Lei 1330/86, em homenagem a Clóvis Lourenço Dias Guerra, filho de Adayl Lourenço dias Guerra e Romilda Guerra, nasceu em Anápolis-Goiás no dia 24/10/34 e faleceu em 09/01/76. Cursou advocacia e exerceu várias funções públicas e destacou-se como Superintendente de Ensino de Anápolis.

A Unidade Escolar passou por várias ampliações. No ano de 1980, na administração do Dr. Decil de Sá Abreu a Escola foi ampliada com mais quatro salas de aula. Em 1992 foi construída uma quadra de esportes, muro da Escola e uma sala de aula, na gestão do prefeito Dr. Anapolino Silvério de Faria e na administração do prefeito Wolney Martins de Araújo, através do convênio com o FNDE-MEC houve ampliação de duas salas de aula. No ano de 1999 e 2000 foram construídas duas salas de aula, com o apoio da comunidade e prefeitura. No ano de 
2003 foi construído o depósito para merenda escolar e em 2004 foi construída uma sala para atendimento dentário com o apoio do Rotary e prefeitura municipal.

A Instituição atende a comunidade estudantil (do sexo masculino e feminino) com faixa etária a partir de 06 até acima de 60 anos, que são a maioria dos alunos da EJA; Grande parte dos estudantes moram perto da escola ou nos bairros circunvizinhos e pertencem à classe social média baixa.

A escola possui 01 diretora, 01 coordenador geral, 05 coordenadores (pedagógicos e técnicos), 38 professores, 08 auxiliares administrativos, 10 auxiliares de serviços gerais, 09 merendeiras e 04 vigias.

As diretoras que por aqui passaram foram às seguintes: Nanci de Carvalho Pádua - 1978 a 1983; Ilda Pereira Braga Campos - 1984 a 1992; Vânia Márcia de Faria Martins - 1992 a 1997; Ivôine Brasil Santos Pachecol - 1998 a 2006, e atualmente Letícia da Silva Faria que iniciou sua gestão em abril de 2006 até a presente data.

A EJA foi implantada pela diretora Ivôine Brasil Santos Pachecol, funcionando no turno noturno desde $\mathrm{o}$ ano de 2001, com autorização de reconhecimento № 5237 pelo CEE - Conselho Estadual de Educação.

\section{IV - PROBLEMA}

Diante das dificuldades apresentadas em sala de aula, - já detectadas desde épocas anteriores pelos professores -, por motivos tais como: violência pelo uso de drogas, evasão escolar por submissão ao marido, sentimento de inferioridade e desemprego devido a pouca escolaridade e qualificação profissional, cabe-nos trabalhar estes assuntos de forma mais abrangente sem despertar diretamente nos alunos a rejeição. "Cada caminho é apenas um entre um milhão de caminhos... Esse caminho tem coração?... Se tiver, o caminho é bom, se não, não tem utilidade" (Castaneda, 2006). Desta forma, coloca-se o problema do PIL: - como abranger as situações tão vastas e delicadas perante o mundo agressivo vivenciado por cada um? Como promover a elevação da auto-estima do aluno da EJA da Escola Municipal Clovis Guerra?

Para Mruck 1998, foram relacionadas cinco razões para o estudo científico da auto-estima: "1) é mais complexo do que se possa parecer, pois está associado com outros aspectos da personalidade; 2) está relacionada à saúde mental ou bem estar pscicológico; 3) a sua carência se relaciona com certos fenômenos mentais 
negativos como depressão e suicídio (não é o nosso foco); 4) é conceito relevante às ciências sociais; 5) elevada relevância social obtida atualmente."

Aproveitando o que o alunos traz de experiência adquirida, elaboramos os planos com as ações para que o aluno se sentisse inserido na escola como uma parte positiva na vida de cada um. As estratégias foram várias, dentre elas: leitura, interpretação e discussão de textos diversos abordando os temas que de início eram considerados polêmicos (e que depois foram compreendidos) tais como droga, abuso com a mulher, discriminação (abrangendo várias áreas) e desemprego, trabalhos artísticos e dança.

Para buscar está compreensão nos apoiamos em Urie Bronfenbrenner 1995, "a abordagem ecológica, procura não só descrever e explicar os efeitos do ecossistema do indivíduo, mais também busca oferecer subsídios para a elaboração de programas de intervenção social" e nos trouxemos para a sala palestrantes para fazer com que este aluno se incluísse no meio social ao qual pertence, levando em consideração à criação, o desenvolvimento desse indivíduo, as experiências adquiridas durante a vida, o temperamento (biologicamente determinado) e personalidade (moldada conforme o ambiente social).

Assim, o aluno chegou ao final do semestre com uma visão mais global e se sentiu parte desta globalização.

\section{V - JUSTIFICATIVA}

Elaborar um projeto e desenvolvê-lo com competência para conseguir os objetivos almejados não é fácil; Assim sendo, este projeto foi idealizado em equipe e está sendo trabalhado com os alunos da EJA da Escola Municipal Clovis Guerra em Anápolis, Avenida Planalto Qd. 12 Lote 02 Vila Jaiara, no ano de 2010, visando um aprendizado com transformação para o educando da EJA. “... toda ação cultural é sempre uma forma sistematizadora e deliberada de ação que incide sobre a estrutura social, ora no sentido de mantê-la como esta ou mais ou menos como esta, ora no de transformá-la" (FREIRE, 1987), para estabelecer um ambiente e determinadas relações que facilitem a auto-estima do aluno da EJA. Para aprender é necessário que aja um clima e locais adequados constituídos de confiança, aceitação, respeito mútuo e sinceridade. A aprendizagem é conseguida quando há condições que estimulam o trabalho e o esforço. Foi preciso criar estratégias de auto-valorização com ambiente seguro e propício para oferecer oportunidades de 
participação, num clima de compromisso que promovesse a interação de afeto e companheirismo dos alunos da EJA, gerando sentimentos de segurança e contribuição positiva e ajustada no comportamento de cada um.

Em virtude do alto índice de violência presenciado pelos professores, pela falta de apoio em casa e observar a evasão escolar por submissão, também pelo fato de os alunos chegarem atrasados aos bancos escolares e faltarem-Ihes emprego digno causam um problema sério de baixa auto-estima, havendo necessidade de um trabalho minucioso para amenizar as conseqüências vindouras, porque "A existência, porque humana, não pode ser muda, silenciosa, nem tampouco pode nutrir-se de falsas palavras, mas de palavras verdadeiras, com que os homens transformam o mundo. Existir, humanamente, é pronunciar o mundo, é modificá-lo". (FREIRE, 1987)

Considerando tudo isto, o projeto foi elaborado e os objetivos, aos poucos, estão sendo conseguidos; foi pensando neste aluno que Paulo Freire lançou a semente para os jovens e adultos ingressarem no mundo do conhecimento escolar, levando em consideração que o indivíduo está em constante transformação e sempre disposto a aprender novas coisas valorizando ainda mais o conteúdo que já adquiriu durante toda a sua existência.

O professor criou um ambiente motivador com palestras, trabalhos em grupo, atividades extraclasse, música, dança que gerou uma auto-confiança para enfrentar os desafios propostos pela vida; desta forma os resultados foram os melhores, diante da aceitação e avaliação dos alunos, para melhorar a auto-estima de cada um.

\section{VI - OBJETIVO GERAL}

- Orientar o aluno para as diversidades da cidadania, promovendo elevção da auto-estima.

\section{1 - OBJETIVOS ESPECÍFICOS}

- Propiciar o conhecimento sobre as causas do uso de drogas (lícitas e ilícitas);

- Argumentar as consequêencias pelo consumo de drogas (lícitas / ilícitas);

- Esclarecer as conquistas conseguidas pela mulher nas últimas décadas e escolher dados para a melhoria de cada um;

- Trabalhar questões que envolvam o valor individual como pessoa; 
- Proporcionar conhecimentos para facilitar o ingresso desse aluno no mercado de trabalho.

\section{VII - METODOLOGIA}

Palestras ministradas por pessoas qualificadas, com temas interessantes ao desenvolvimento sociocultural e afetivo do aluno da EJA;

- Leitura de textos diversos, abrangendo assuntos relacionados aos problemas detectados;

- Apresentação de filmes, onde a persistência faz vencedores, para melhorar a auto-estima;

- Formulação de questionário (contido no apêndice deste trabalho) para conhecer o sentimento do aluno em relação a vida que ele está levando, e as expectativa com a escola e o método de ensino/aprendizagem da EJA;

- Compreensão dos problemas gerados durante o período da aula, fazendo intervenções para detectar tais situações;

- Aplicação de trabalhos grupais, com temas específicos relacionados à problemática detectada;

- Interação com o aluno, fazendo-o sentir-se útil para si e para a sociedade a qual ele pertence;

- Visitação a lugares até então considerados impossíveis por eles, como exemplo, assistirem a uma peça teatral ou a um show musical;

- Valorização do trabalho individual como fonte de renda para o conhecimento do grupo e para o crescimento social, valorizando o trabalho e a remuneração conseguida pelo fruto do mesmo;

- Apresentações artísticas no salão da escola, pelos alunos e por convidados;

- Realização de jogos de interclasse entre alunos da EJA (noturno) e Ensino Regular (matutino);

- Culminância com a dança da quadrilha na festa junina, entre alunos da EJA (noturno) e Ensino Regular (matutino)

- Uso da experiência pessoal para o crescimento da equipe.

\section{VIII - CRONOGRAMA}




\begin{tabular}{|l|c|}
\hline \multicolumn{1}{|c|}{ ATIVIDADES } & PERÍODO \\
\hline Início do Projeto & Fevereiro \\
\hline Questionário Aplicado aos Alunos & $1^{\text {a }}$ quinzena de fevereiro \\
\hline Palestra (As Drogas e suas Consequências) & $2^{\underline{a}}$ quinzena de fevereiro \\
\hline Palestra (Auto-estima e Valorização pessoal) & $1^{\underline{a}}$ quinzena de março \\
\hline Tabulação do questionário & $1^{\frac{a}{a}}$ quinzena de abril \\
\hline $\begin{array}{l}\text { Trabalho interdisciplinar (EJA - Cores e Valores } \\
\text { na Copa do Mundo) }\end{array}$ & $2^{2^{\mathrm{a}}}$ quinzena de abril \\
\hline $\begin{array}{l}\text { Apresentação artística dos alunos (EJA - Cores } \\
\text { e Valores na Copa do Mundo) }\end{array}$ & \\
\hline Entrevista com alunos & $1^{1^{\mathrm{a}}}$ quinzena de maio \\
\hline Finalização do projeto com o roteiro & \\
\hline
\end{tabular}

\section{IX - PARCEIROS}

- Palestrantes (Sr. Elias e Sr. Jailton);

- Diretora;

- Coordenadora;

- Professores;

- Alunos.

\section{X - RECURSOS}

- Materiais didáticos disponíveis na escola;

- Questionário investigativo para uma maior aproximação do aluno/professor;

- Aparelhos tecnológicos;

- Laboratório de informática.

\section{XI - ACOMPANHAMENTO E AVALIAÇÃO}

"Devemos ensinar as perguntas e não as respostas. As respostas nos permitem andar em terra firme. Mas somente as perguntas nos permitem entrar pelo mar desconhecido" (ALVES, 2005). Assim sendo, como mediadores do conhecimento, levantamos a questão e deixamos os nossos alunos viajarem na imaginação, buscando os saberes, para em seguida, dividirem uns com os outros as 
descobertas. Nesta sequência, o aluno estará participando ativamente do processo ensino aprendizagem, sendo avaliado no todo, através do interesse e participação.

Levando em consideração a compreensão do que foi trabalhado durante as aulas, o aperfeiçoamento nas atividades executadas, o desenvolvimento ao longo do semestre e as mudanças de atitude dos alunos da EJA, verificamos que eles também fizeram as avaliações tanto do próprio comportamento quanto das ações sugeridas pelo professor durante as realizações das atividades propostas, que geraram atitudes de diferentes níveis (para melhor) dos próprios alunos da EJA em nossa Instituição de Ensino.

\section{XII - RESULTADOS ALCANÇADOS}

A aplicação do PIL, A Importância de Valorizar a Auto-Estima na Educação de Jovens e Adultos, na Escola Municipal Clovis Guerra, foi um trabalho que rendeu bons frutos; tivemos duas palestras: uma sobre auto-estima e outra sobre drogas.

Em todas as palestras, houve comentários positivos sobre os temas, conforme o resultado do questionário aplicado aos alunos; Nas respostas, eles disseram que querem deixar o vício para se tornarem pessoas "do bem" (de acordo com as palavras deles), como podemos ler a seguir:

"Preciso deixar de puxar este fumo, pra não ser discriminado e jogado na sarjeta daqui um tempo". (J. P. SILVA, 22 anos, aluno do $2^{\circ}$ semestre)

Falaram ainda que querem, e que precisam, estudar mais para mostrar que são capazes de vencer os obstáculos e que querem um emprego digno, visando a melhoria financeira para a família, conforme disse: .

"Eu quero dar um futuro melhor para minha família e só vou conseguir isto se eu estudar muito, porque assim vou ganhar mais".." (Joaquim Batista L. Filho, 62 anos, aluno do $5^{\circ}$ semestre)

Quando levamos o trabalho sobre a Copa (no mês de abril), o entusiasmo tomou conta de todos e, durante o desfile (eles com as bolas que fizeram), verificamos que a vaidade havia tomado conta de todos, principalmente das mulheres, que mudaram totalmente o visual a fim de se mostrarem mais bonitas na passarela;

\footnotetext{
${ }^{1}$ Nome fictício, para não ferir a integridade do aluno.
} 
e mesmo ao término das apresentações, observamos que havia um enorme sorriso no rosto de cada um,como disse:

"Eu tô muito feliz, professora; até fui no salão arrumar o cabelo, assim eu me senti mais bonita. Este é o melhor dia da minha vida". (Romilda Rodrigues, 32 anos, aluno do $5^{\circ}$ semestre)

Com estes pequenos detalhes para nós, a apresentação do trabalho que eles fizeram em sala, na confecção das bolas, observamos que foi algo especial na vida de cada um, levando o amor próprio reconquistado naquele momento e, nos lembramos de Neil Armstrong em 1969, quando pisou em solo lunar, dizendo: "Este é um pequeno passo para o homem, mas um salto gigantesco para a humanidade".

Quando eles desfilaram com as bolas confeccionadas por eles mesmos, nas aulas de geometria, foi - por eles - considerado algo inédito, pois eles se achavam incapazes de realizarem tal trabalho; assim, viram que qualquer que seja o trabalho, eles irão com determinação e perseverança e serão capazes de realizar.

$\mathrm{Na}$ realização dos jogos de interclasse os alunos da EJA se sentiram tão realizados quanto os do Ensino Regular.

$\mathrm{Na}$ culminância durante a dança da quadrilha na festa junina, os alunos da EJA se produziam a caráter, interpretaram personagens folclóricas e esbanjaram alegria.

\section{XIII - RELATÓRIO}

Aos orientadores da Universidade de Brasília - UNB

Especialização em Educação na Diversidade e Cidadania, com ênfase na EJA

Brasília - DF 
Através do presente, estaremos relatando os trabalhos realizados em sala de aula na Escola Municipal Clovis Guerra, tão logo foram detectados os problemas (violência pelo uso de drogas, auto-estima baixa por falta de emprego, submissão e baixa escolaridade), começamos a desenvolver o Projeto: A importância de valorizar a auto-estima na Educação de Jovens e Adultos, conforme especificamos abaixo: 01 - Aplicação do questionário para conhecer o desejo de cada um, as perspectivas para o futuro, os anseios e os medos; As respostas nos surpreenderam, fazendonos enfocar no aspecto da auto-estima, conforme as respostas contidas na tabulação anexa;

02 - Ministrada a palestra sobre drogas, com o Tenente Coronel Elias, percebemos que, ao longo das conversas com os alunos, muitos almejam se livrarem do vício e, com os esclarecimentos transmitidos pelo palestrante, este desejo aumentou, fazendo-os nos procurarem para desabafar sobre o problema;

03 - Proferida a palestra sobre auto-estima e valorização pessoal, muitos se mostraram mais interessados nas aulas, com o objetivo de concluírem o Ensino Fundamental e prosseguirem com os estudos, visando uma melhoria profissional e , posteriormente, dar mais conforto para a família;

04 - O trabalho transdisciplinar "EJA Cores e Valores na Copa do Mundo 2010", levou os alunos a se dedicarem, realizar apresentação artística, fazendo-os sentirem que são importantes para si e também para a sociedade, não só de Anápolis, mas para o mundo, como um brasileiro que quer ver seu time vencer a copa; Neste contexto, aconteceram os jogos do Interclasse, que foi uma motivação a mais para cada um;

05 - Aconteceu o interclasse entre os alunos da EJA e alunos do $9^{\circ}$ ano do ensino regular; quando os alunos da EJA vieram para o matutino a fim de jogarem e organizar a torcida; no jogo houve empate entre as equipes, proporcionando momentos de alegria entre eles;

06 - Cada atividade levada para a sala de aula, com os conteúdos programados está voltada para o crescimento estudantil e, acima de tudo, da valorização pessoal, levando-os a crer que eles são tão importantes no mundo como a "água para a planta", assim, os resultados são vistos a cada dia, quando percebemos que já está havendo mudança de atitude de cada um; 
07 - Foram feitas entrevistas com os alunos, procurando elevar o valor pessoal, formulando perguntas sobre o motivo da volta às aulas e a respeito das perspectivas para o futuro, bem relacionada ao momento escolar de hoje, onde ficaram gravados depoimentos feitos por eles, no CD anexo ao trabalho de conclusão;

08 - A culminância de todos os trabalhos realizados no semestre, com apresentações artísticas, exposição dos trabalhos realizados em sala (escritos e artísticos), música, dança, encerrando com um jantar;

09 - No dia 26/06/2010, durante a festa junina, ocorreu a grande dança da quadrilha, formada por alunos da EJA e do Ensino Regular, promovendo uma interação dos dois turnos com harmonia e dedicação por parte de ambos.

Os objetivos foram alcançados, visto que acompanhamos passo-a-passo os alunos, após detectar o problema, e as ações foram direcionadas e desenvolvidas durante o semestre e, conforme perspectiva e incentivo de continuar o projeto nos anos seguintes; com passos decisivos, os alunos seguirão seu trajeto de cabeça erguida para alcançar o sonho a muito tempo desejado e que, com o projeto, viram que são capazes de ultrapassar as barreiras encontradas pelo caminho.

Anápolis, 03 de Junho de 2010.

\author{
AMÁLIA BALIZA RODRIGUES \\ CLEIDE CORDEIRO DOS SANTOS \\ ELAINE MARIA MACHADO BARBOSA \\ RENATA CÂNDIDO DA SILVA
}

\title{
XIV - REFERÊNCIA
}

ALVES, Rubem. Filosofia as ciência: introdução ao jogo e suas regras. 9a 
edição, Editora Loyola. MG. 2005.

BRONFENBRENNER, Urie. Developmental ecology through space and time: a future prespective. Washinghton. DC: American Psycological Association. 1995

CASTANEDA, Carlos. Porta para o Infinito. Editora Nova Era. Brasil. 2006.

FREIRE, Paulo. Pedagogia do Oprimido. 20를 Edição. Rio de Janeiro: Paz e Terra, 1987.

MRUCK, C. Auto-estima: Investigation, teoria e prática. 1998.

XV - APÊNDICES

15.1 - TABELA 1

\begin{tabular}{|c|c|}
\hline Problemas & № de Alunos \\
\hline Patrão & 9 \\
\hline Problemas Familiares & 23 \\
\hline Saúde & 4 \\
\hline Conciliar Emprego / Estudos & 14 \\
\hline
\end{tabular}




\begin{tabular}{|cc|}
\hline Dívidas & 2 \\
\hline Dificuldades Financeiras & 13 \\
\hline Socialização & 5 \\
\hline Trabalho Excessivo & 12 \\
\hline Não tem Problemas & 12 \\
\hline Dificuldade de Aprendizagem & 2 \\
\hline Viver Escondida & 1 \\
\hline Uso de Drogas & 6 \\
\hline Não Gosta de Si Mesmo & 7 \\
\hline Desemprego & 4 \\
\hline
\end{tabular}

Tabela 1 - Quais são os maiores problemas de sua vida escolar?

\section{2 - TABELA 2}

\begin{tabular}{|cc|}
\hline O Que Mudaria & № de Alunos \\
\hline Não Mudaria Nada & 14 \\
\hline Mudaria Tudo & 11 \\
\hline Mudaria o Jeito de Ser & 28 \\
\hline O Trabalho & 4 \\
\hline Mudaria com Deus & 2 \\
\hline Não Teria Interrompido os Estudos & 10 \\
\hline Relacionamento Familiar & 9 \\
\hline Mudaria o Passado & 10 \\
\hline Os Amigos & 3 \\
\hline Nunca Ter Usado Drogas & 3 \\
\hline Relacionamento com as Pessoas & 6 \\
\hline Não Voltar para o Brasil & 1 \\
\hline Ser Rico & 8 \\
\hline
\end{tabular}

Tabela 2 - Se você fosse mudar algo em sua vida, o que mudaria?

15.3 - TABELA 3

\begin{tabular}{|cc|}
\hline Sonhos & № de Alunos \\
\hline Estabilidade Financeira & 21 \\
\hline Ter Casa Própria & 13 \\
\hline Concluir os Estudos & 33 \\
\hline Ter Emprego Melhor & 19 \\
\hline Ter uma Família Estruturada & 12 \\
\hline Comprar um Carro & 8 \\
\hline
\end{tabular}




\begin{tabular}{|cc|}
\hline Casar e Ter Família & 17 \\
\hline Reconciliação dos Pais & 1 \\
\hline Ter Alegria / Ser Feliz & 20 \\
\hline Saúde & 1 \\
\hline Ficar Rico & 9 \\
\hline
\end{tabular}

Tabela 3 - Quais são os seus sonhos?

15.4 - ILUSTRAÇÂO 1 


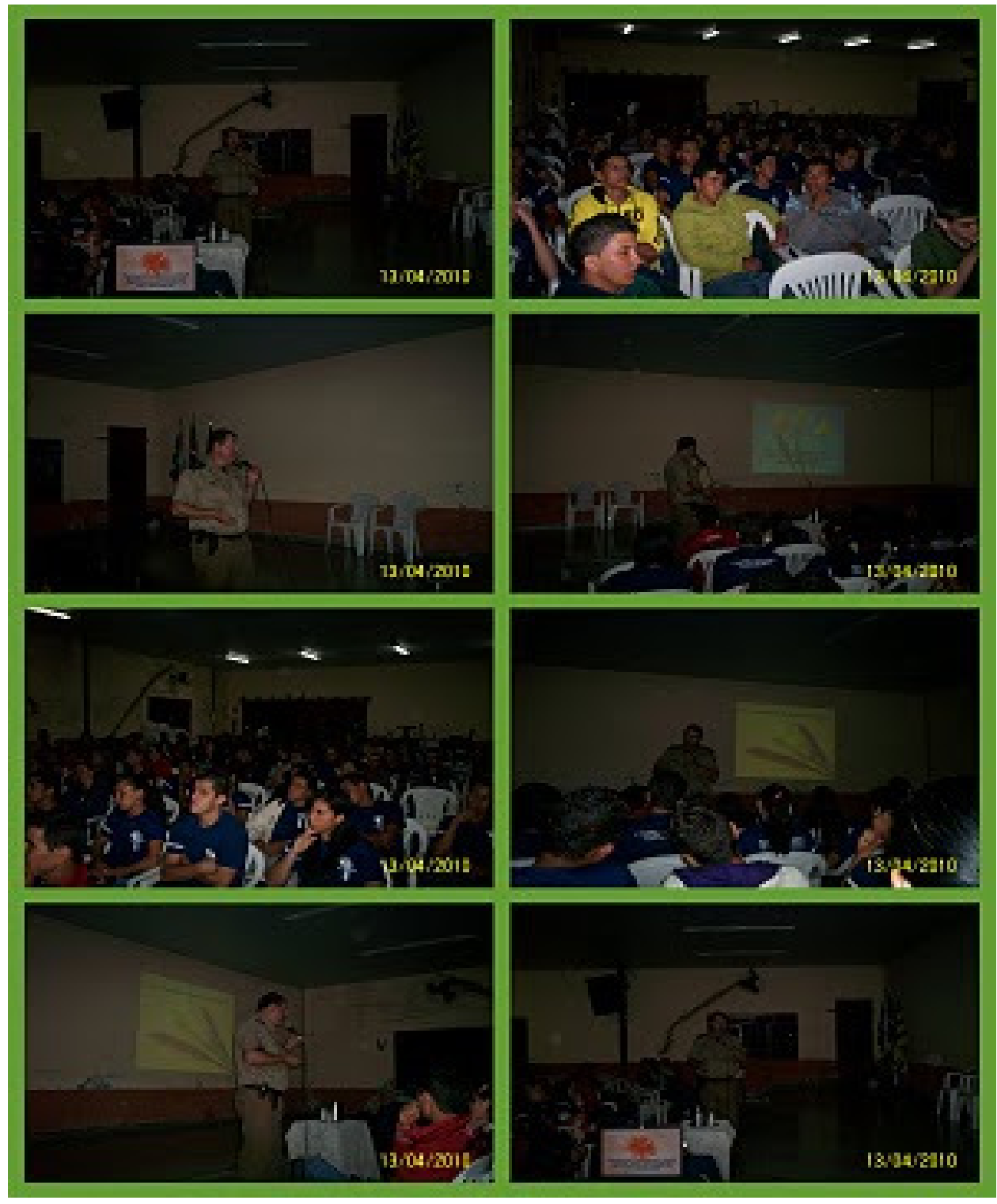

Figura 1 - Fotos com o palestrante Sr. Elias, palestra: As drogas e suas consequências.

15.5 - ILUSTRAÇÂO 2 


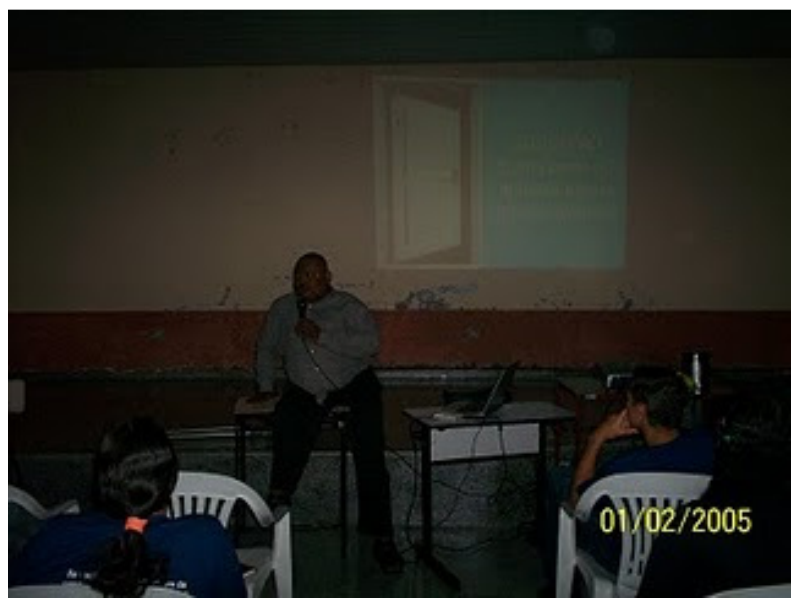

Figura 2 - Foto com o palestrante Sr. Jailton Nascimento, palestra sobre auto-estima e Valorização pessoal.

15.6 - ILUSTRAÇÂO 3

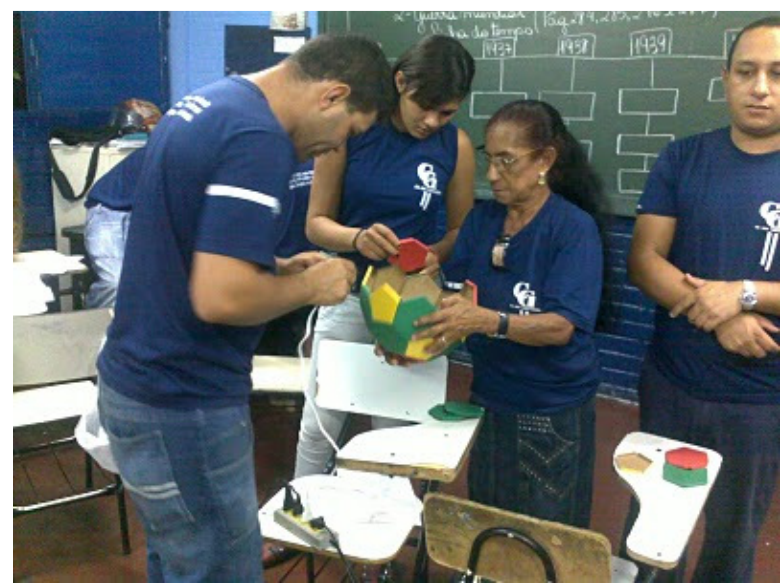

Figura 3 - Foto com alunos da EJA confeccionando bolas para o trabalho interdisciplinar (EJA - Cores e Valores na Copa do Mundo)

15.7 - ILUSTRAÇÂO 4 


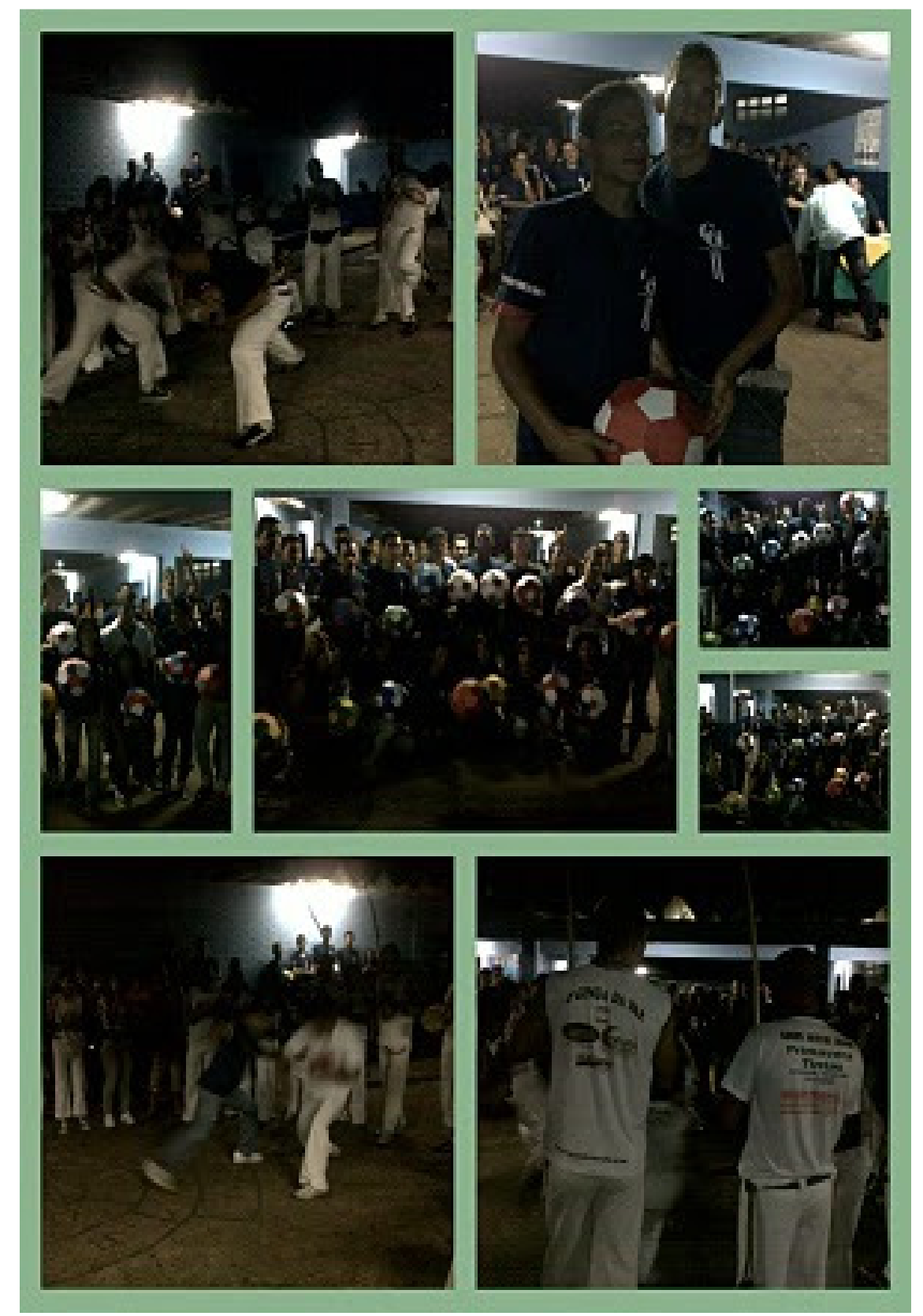

Figura 4 - Fotos da apresentação artística dos alunos da EJA (EJA - Cores e Valores na Copa do Mundo)

15.8 - ILUSTRAÇÂO 5 


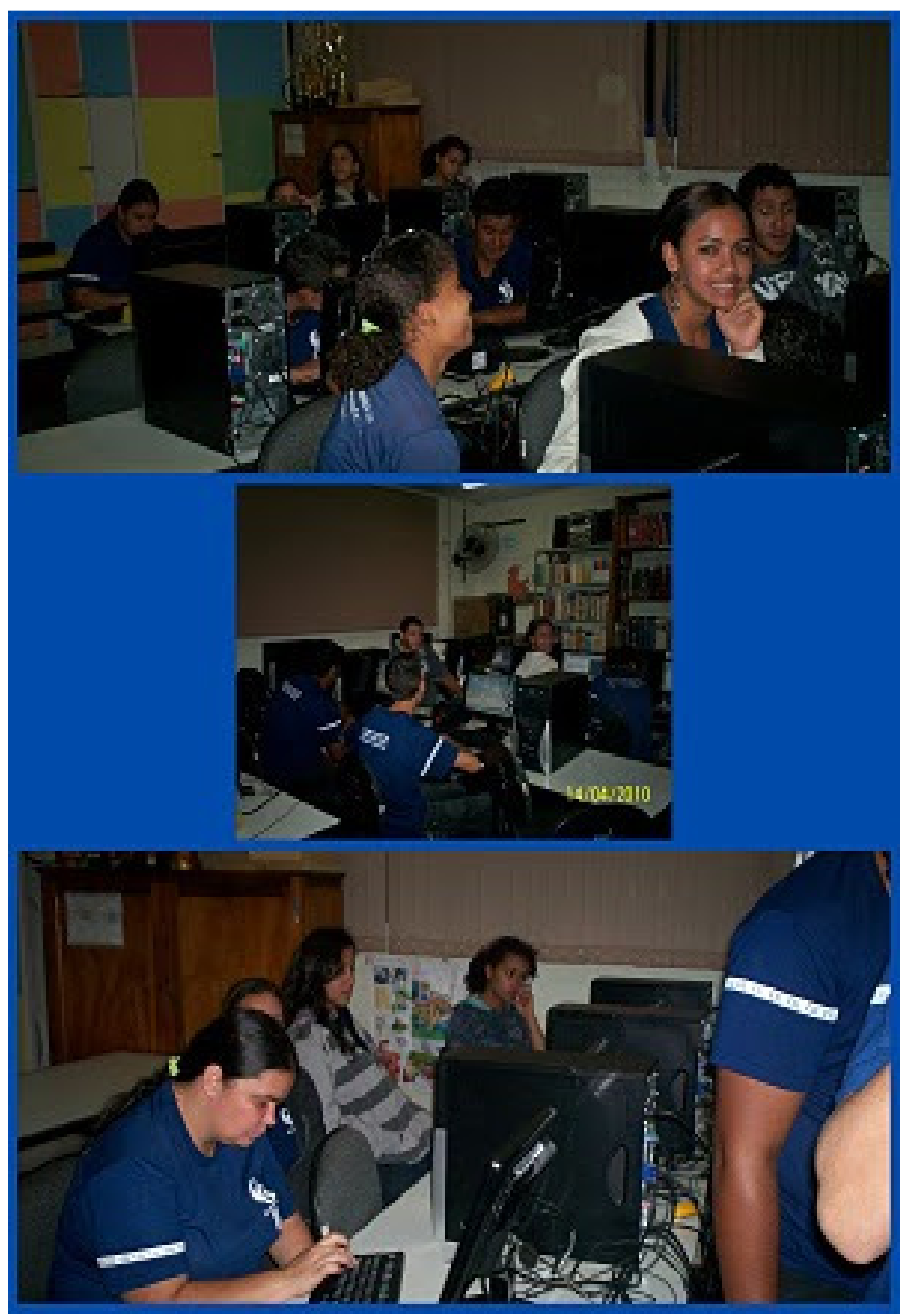

Figura 5 - Fotos com os alunos da EJA fazendo atividades no laboratório de informática. 


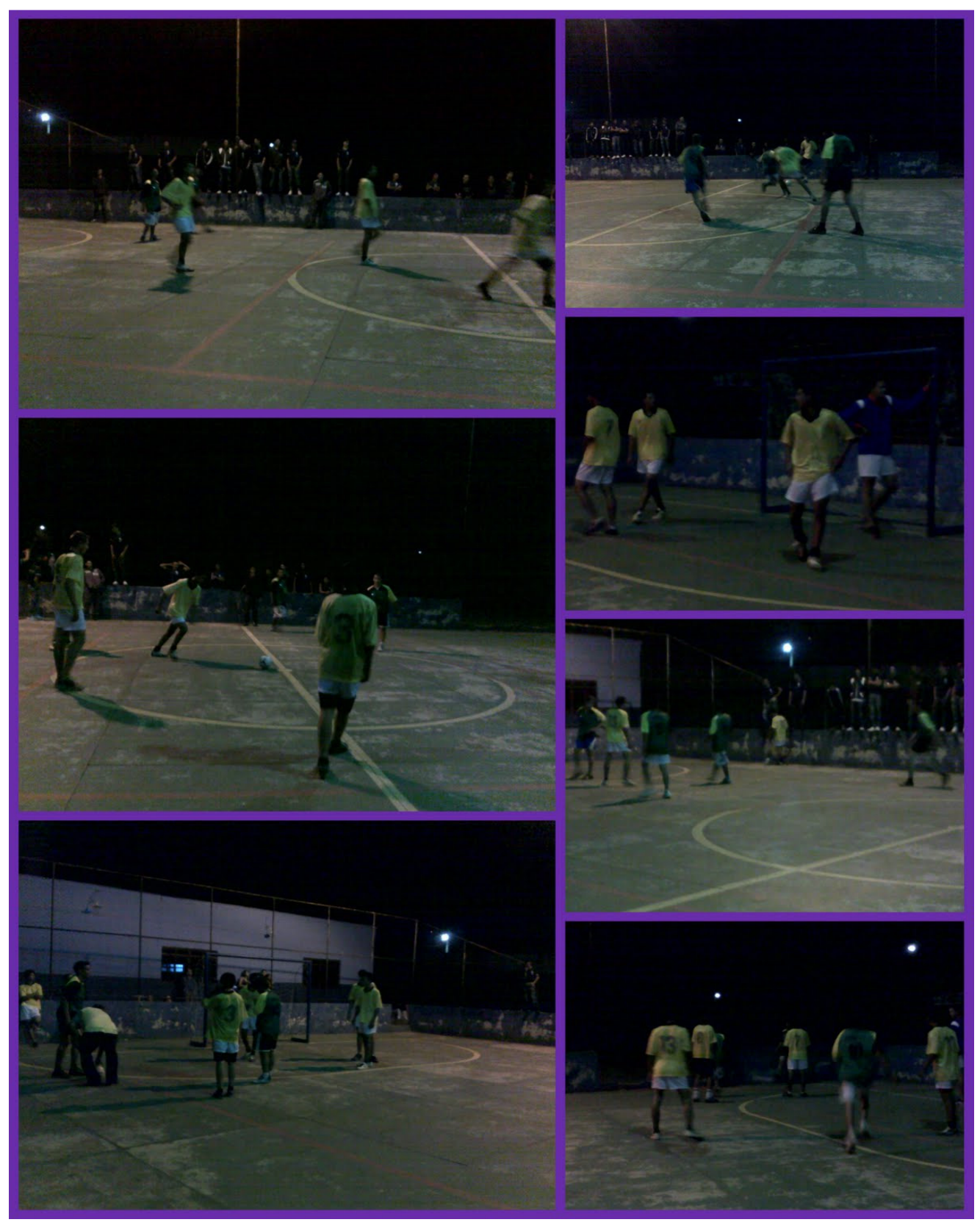

Figura 6 - Fotos do interclasse entre alunos da EJA (noturno) e alunos do Ensino Regular (matutino).

15.10 - ILUSTRAÇÂO 7 

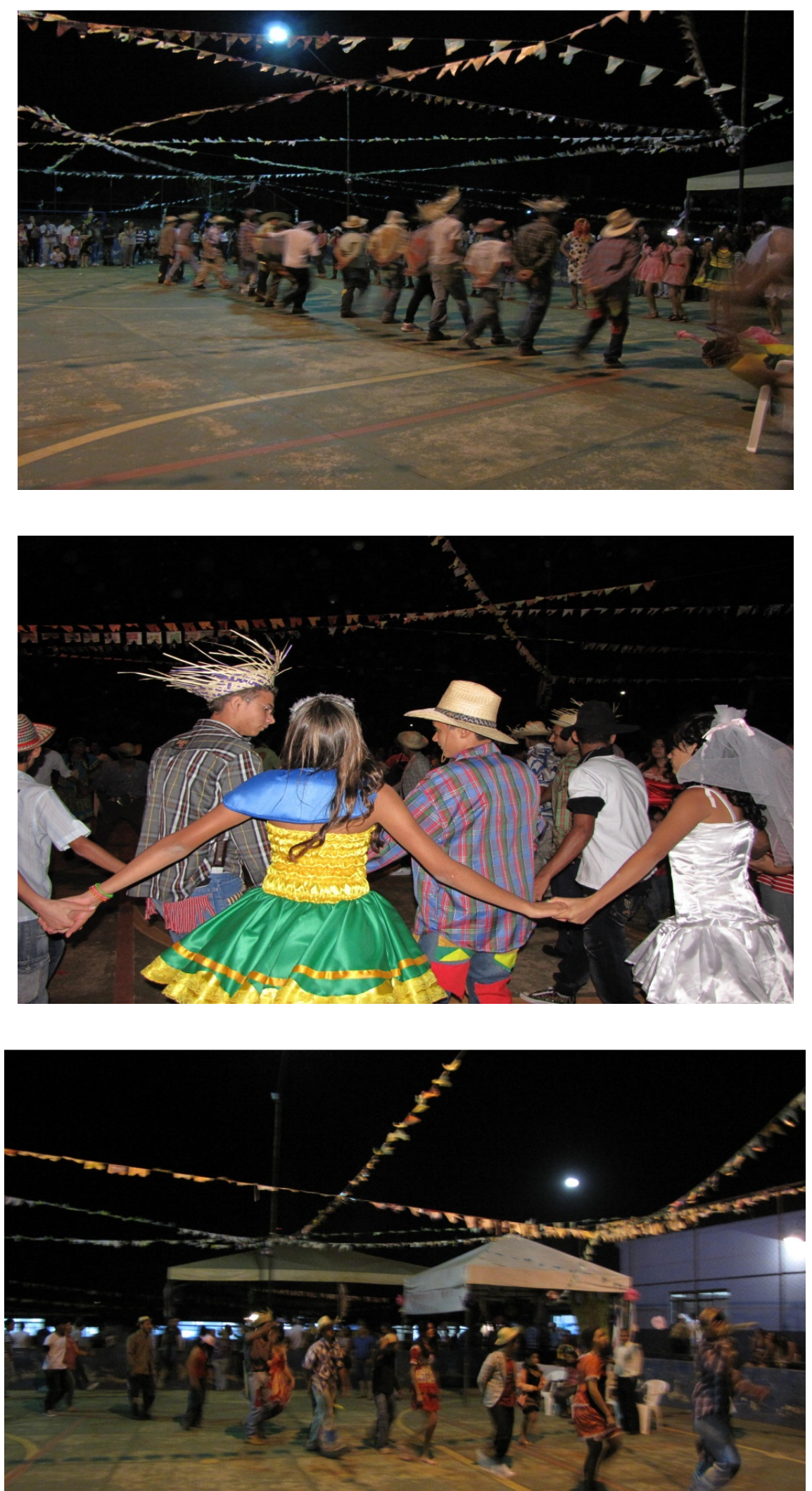

Fotos da culminância do projeto entre os alunos da EJA (noturno) e Ensino Regular (matutino) na Festa Junina 
15.11 - ATIVIDADE REALIZADA - LÍNGUA PORTUGUESA

Dinâmica:

- Entrega para cada aluno um saquinho com algodão;

- Dar cinco minutos para cada um fazer o que quiser com o saquinho de algodão;

- OBS: O aluno poderá rasgar o saquinho, jogá-lo no lixo, dar para alguém ou mesmo guardá-lo;

- Distribuir o texto: A coisa mais valiosa;

- Fazer a leitura em voz alta;

- Fazer a reflexão;

- Discutir sobre o valor da amizade.

Texto: A coisa mais valiosa

Havia uma pequena aldeia onde o dinheiro não entrava. Tudo o que as pessoas compravam, tudo o que era cultivado e produzido por cada um, era trocado.

A coisa mais importante e mais valiosa era o amor. Quem nada produzia, quem não possuía coisas que pudessem ser trocadas por alimentos ou utensílios, dava o seu carinho.

O carinho era simbolizado por um "floquinho" de algodão. Muitas vezes era normal que as pessoas trocassem floquinhos sem querer nada em troca.

As pessoas davam carinho, pois sabiam que receberiam outros, num outro momento, ou outro dia.

Um dia, uma mulher muito má, que vivia fora da aldeia, convenceu um pequeno garoto a não mais dar seus floquinhos.

Dessa forma, ele seria a pessoa mais rica da cidade e teria o que quisesse. lludido pelas palavras da malvada, o menino, que era uma das pessoas mais populares e queridas da aldeia, passou a juntar carinhos e em pouquíssimo tempo sua casa estava repleta de floquinhos, ficando até difícil de circular dentro dela.

Daí então, quando a cidade já estava praticamente sem floquinhos, as pessoas começaram a guardar o pouco carinho que tinham, e toda harmonia da aldeia desapareceu.

Surgiu a ganância, a desconfiança, o primeiro roubo, o ódio, a discórdia, as pessoas se xingaram pela primeira vez e passaram a ignorar-se pelas ruas. Como era o mais querido da aldeia, o garoto foi o primeiro a sentir-se triste e sozinho, o que o fez procurar a velha para perguntar e dizer-Ihe se aquilo fazia parte da riqueza 
que ele acumularia. Não a encontrando mais, ele tomou uma decisão: pegou uma grande carriola, colocou todos os seus floquinhos em cima e caminhou por toda a cidade distribuindo aleatoriamente seu carinho.

A todos que dava carinho, apenas dizia:

- Obrigada por receber meu carinho.

Assim sem medo de acabar com seus floquinhos, ele distribuiu até o último carinho sem receber um só de volta.

Sem que tivessem tempo de sentir-se sozinho e triste novamente, alguém caminhou até ele e lhe deu carinho. Um outro fez o mesmo... mais outro... e outro..., até, definitivamente, a aldeia voltar ao normal.

Ao final do texto foi dito aos alunos que nunca devemos fazer as coisas pensando em receber algo em troca.

\subsection{2 - ATIVIDADE REALIZADA - LABORATÓRIO DE INFORMÁTICA}

No laboratório de informática realizaram-se várias atividades interdisciplinares, entre elas podemos citar a seguinte:

O laboratório de informática possui computadores cuja plataforma é Linux 2.0, oferecida pelo MEC, onde vem com vários softwares instalados nos computadores, um deles que foi usado em uma das aulas com os alunos da EJA é o jogo Tux Match, este jogo trabalha a disciplina de matemática, mais especificamente a tabuada, nele os alunos puderam jogar com a velocidade e as operações: adição, subtração, multiplicação ou divisão, proposta pelo professor dinamizador, as vezes jogavam com mais de uma operação, e em várias velocidades. A atividade foi bastante proveitosa, pois os alunos praticaram um pouco da tabuada, pensamento rápido, agilidade para manusear o teclado e também tiveram, mais uma vez, um pouco mais de contato com o computador.

\subsection{3 - ATIVIDADE REALIZADA - MATEMÁTICA}

1 - A mais recente pesquisa do Centro Brasileiro de Informações sobre Drogas Psicotrópicas, realizada com 48 mil estudantes de colégios públicos , comprova: dois em cada três jovens já beberam aos 12 anos de idade - e um em cada quatro já experimentou cigarros. 


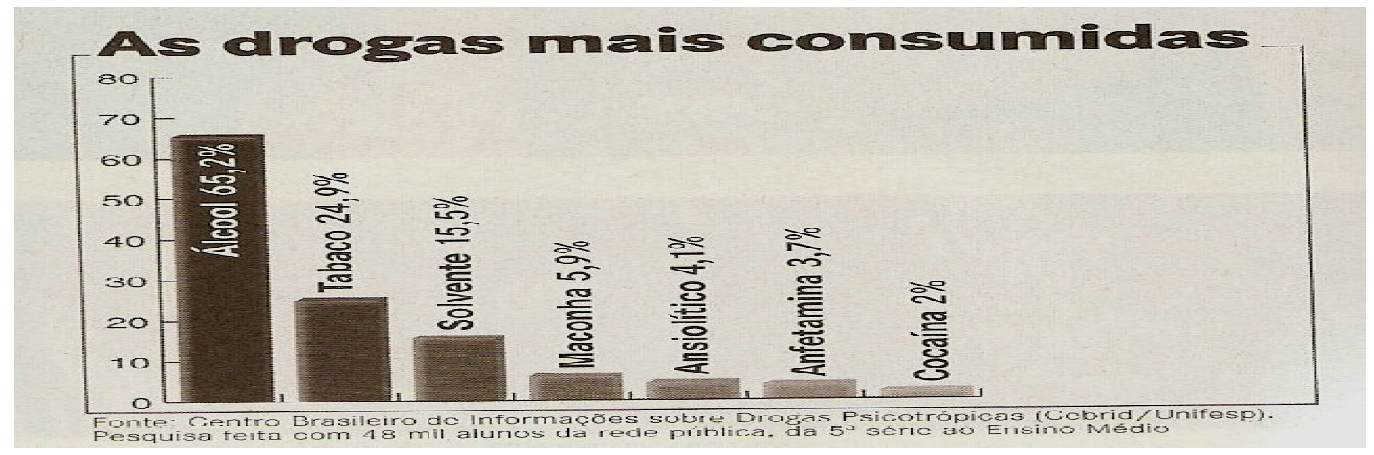

Responda:

a) Faça o arredondamento das porcentagens tornando-as números inteiros.

b) Escreva as porcentagens ( já feito o arredondamento) na forma de fração decimal

c) Agora, escreva as porcentagens na forma de número decimal.

d) “... dois em cada três jovens já beberam aos doze anos de idade”. Qual porcentagem representa os jovens que já beberam?

E os jovens que não beberam?

e) Dos 48 mil pesquisados, quantos são os que já consumiram tabaco?

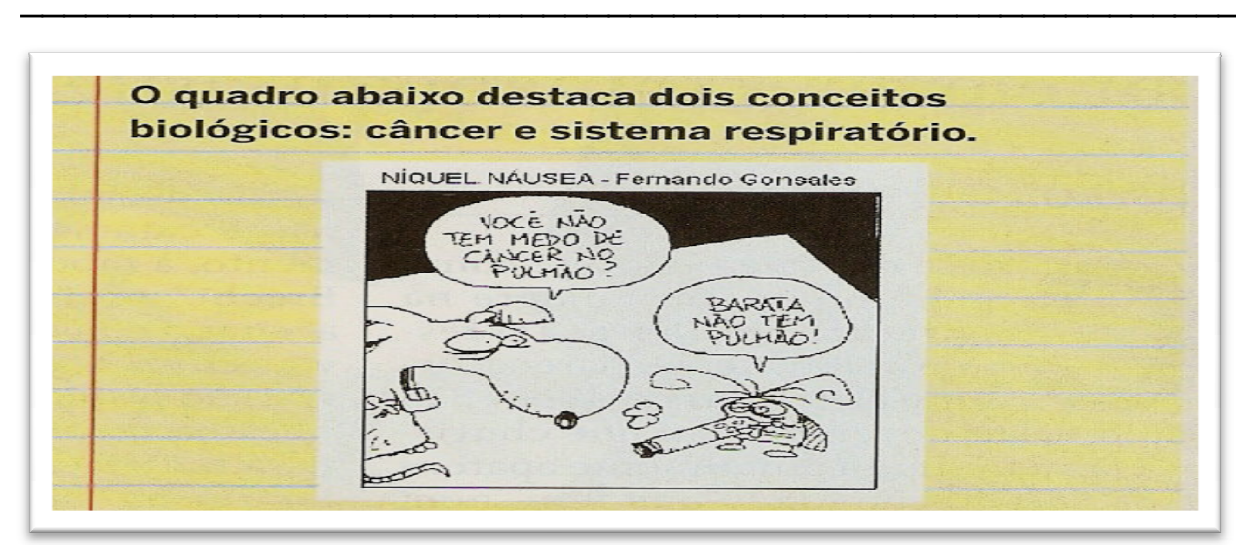

2- Leia:

O cigarro

possui cerca

de 4720

substâncias

tóxicas, das

quais $43 \%$

são cancerígenas. Algumas dessas substâncias estão presentes naturalmente no tabaco (ou fumo) outras são acrescentadas a ele no processo de industrialização. Quanto representa as substâncias cancerígenas? 

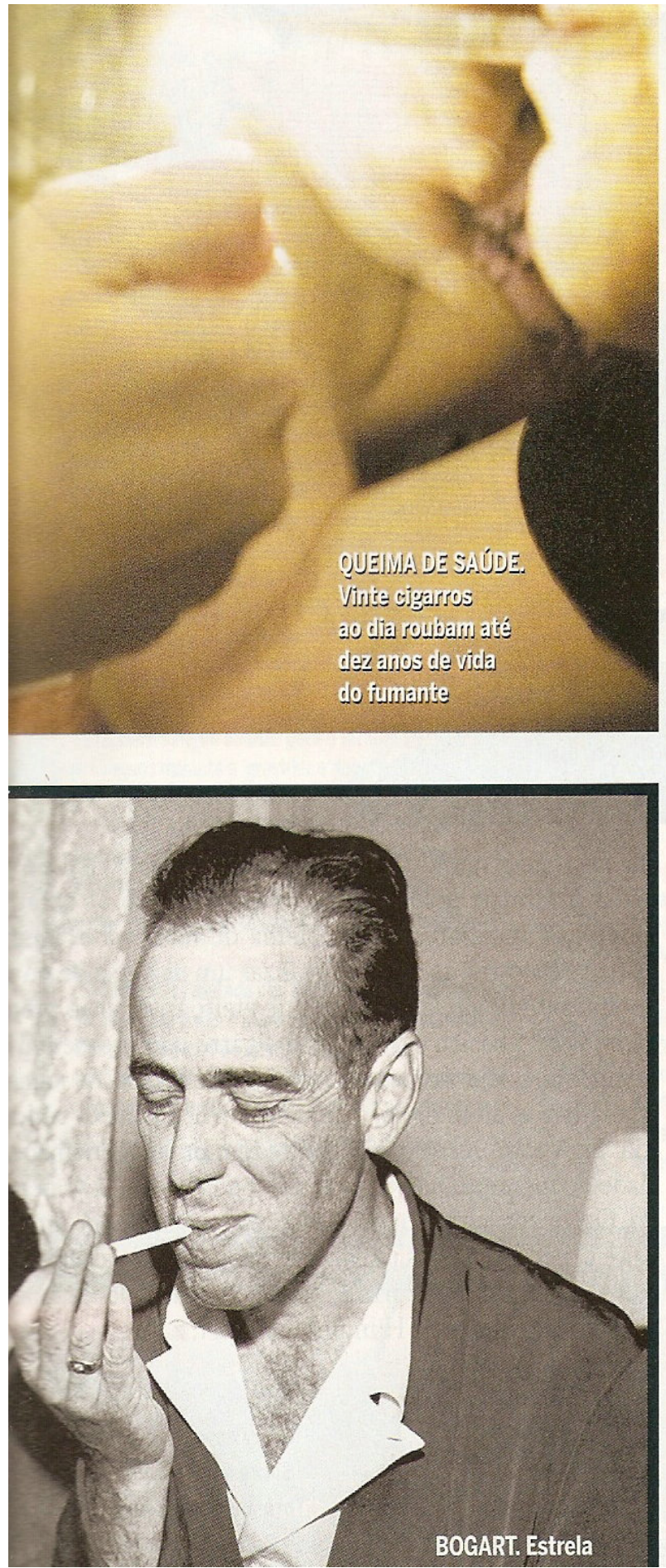

\section{Efeitos do cigarro}

Estudos como o publicado na edição de outubro na revista científica Archives of Internal Medicine tornam possível ver o efeito cumulativo desse hábito que muitos ainda têm como inofensivo. Em 1974, foram examinados 1.658 homens com idades entre 40 e 55 anos (idade média de 47,8 anos), com exames médicos satisfatórios. Nesse grupo havia 614 homens que nunca tinham fumado, outros que tinham fumado e parado ou que fumavam poucos cigarros e, no extremo do grupo, outros 188 fumavam mais de vinte cigarros por dia.

O grupo era bastante homogêneo, inclusive do ponto de vista socioeconômico, composto de empresários finlandeses que não apresentavam doenças crônicas, não tomavam nenhuma medicação regular e que estavam profissionalmente ativos em cargos de responsabilidade. Vivendo em um país que tem indicadores sociais muito elevados, pode-se evidenciar o efeito do tabaco na qualidade de vida de seus usuários. O grupo foi reavaliado 26 anos depois e teve como resultado um amplo quadro de problemas que foram devidamente aquilatados apenas agora. O resultado é rigoroso: 372 homens do grupo original tinham morrido e existe uma relação matemática significativa entre o número de cigarros consumidos e a expectativa de vida.

Vinte cigarros ao dia roubam nada menos que de sete a dez anos de vida ao fumante. Mas o preço não é apenas esse, pois a qualidade de vida se degrada sensivelmente e é apenas na maturidade que esses efeitos se tornam mais visíveis.

O estudo mostra que entre os sobreviventes (idade média de 73 anos), os não-fumantes tinham qualidade de vida significativamente superior ao grupo dos fumantes, mas, ainda mais importante, os anos adicionais eram mais saudáveis. No grupo dos fumantes, a duração de vida foi menor e, além disso, seus últimos anos foram de qualidade de vida muito inferior.

Houve diferença significativa em diversas dimensões estudadas e não apenas na saúde física, mas também afetiva e até mesmo financeira. Outra conclusão do estudo refere-se aos ex-fumantes. Há um efeito residual do cigarro na expectativa e na qualidade de vida, pois, ao longo dos 26 anos de acompanhamento, os ex-fumantes não alcançam os mesmos níveis daqueles que nunca tinham fumado. Isso sugere que é na juventude que a prevenção deve atuar mais fortemente e que melhor do que deixar de fumar é mesmo nunca fumar. 


\section{XVI - BIBLIOGRAFIA}

ARANHA, F. Educadores populares e movimentos populares. Relação de saber. Belo Horizonte: PUC, 2002.

ARROYO, Miguel G. Educação de Jovens e Adultos - um campo de direitos e de responsabilidade pública. IN: SOARES, L. ET AL (orgs). Diálogos na educação de jovens e adultos. Belo Horizonte: Autêntica, 2005.

BARRETO, Vera. Paulo Freire para educadores. São Paulo: Arte Ciência, 1998.

CARVALHO, Edgar de A. Enigmas da cultura. São Paulo: 1999.

CHALUB, Leila Martins. A construção do sujeito pela educação. Revisando Paulo Freire.

FREIRE, Paulo. Pedagogia da indagação. São Paulo: Ed. UNESP, 2000.

FRIGOTTO, Gaudênico. A produtividade da escola improdutiva. Um (re) exame das relações entre educação e estrutura econômica - social capitalista. São Paulo: Cortez, 1984.

GALVANI, Pascal. A auto-informação, ima perspectiva transpessoal, transdisciplinar e transcultural. In: Educação e Transdisciplinariedade , II / coordenação executiva do CETRANS - São Paulo: TRION, 2002.

GRAMSCI, Antônio. Os intelectuais e a organização da cultura. Rio de Janeiro: Ed. Civilização brasileira, 1968.

JUKUPE, Kaká Wera. Tupã Tenondé - A criação do Universo, da Terra e do homem segundo a tradução oral Guarani. São Paulo: Ed. Peirópolis, 1998.

LEONARDI, Vitor. Os navegantes e o sonho - Presença do Oriente na história do Brasil. Brasília: Paraldo, 2005. 
LEVI, Pierre. A inteligência coletiva - por uma antropologia do ciberespaço; Tradução: Luiz Paulo Rounet. São Paulo: Ed. Loyola. 1998.

MARX, K. Engels, F. Obras escolhidas. Vol. 1, Rio de Janeiro: Vitória.

MATURANA, R. Humberto e Varela, G. Francisco. A árvore do conhecimento - as bases biológicas do entendimento humano. Tradução Jonas Pereira dos Santos. São Paulo: Ed. Psy. 1995.

PAIVA, Jane. Educação de Jovens e Adultos: Direito, concepção e sentidos (Tese de Doutorado) Faculdade de Educação. Niterói: RJ. 2005.

REIS, Renato Hilário dos. A constituição do sujeito Político, Epistemológico e amoroso na Alfabetização de jovens e Adultos. Tese de Doutorado. Campinas: Faculdade de educação da Unicamp, 2000.

RIBEIRO, Darcy. O povo brasileiro, a formação e o sentido do Brasil. São Paulo: Companhia das letras. 1995.

RUSSEL, Peter. O buraco no tempo: nossa evolução futura e o significado do agora. Tradução Merle Scoss. São Paulo: Aquariana. 1992.

VIEIRA, M. C. Possíveis impactos das políticas de avaliação na educação de jovens e adultos: o ENCEJA em questão. Educação em Revista. Belo Horizonte: no 43, jun. 2009. 